\title{
Experimental demonstration of a digital maximum likelihood based feedforward carrier recovery scheme for phase-modulated radio-over-fibre links
}

\author{
Guerrero Gonzalez, Neil; Zibar, Darko; Yu, Xianbin; Tafur Monroy, Idelfonso
}

Published in:

LEOS 200821st Annual Meeting of the IEEE Lasers and Electro-Optics Society

Link to article, DOI:

10.1109/LEOS.2008.4688861

Publication date:

2008

Document Version

Publisher's PDF, also known as Version of record

Link back to DTU Orbit

Citation (APA):

Guerrero Gonzalez, N., Zibar, D., Yu, X., \& Tafur Monroy, I. (2008). Experimental demonstration of a digital maximum likelihood based feedforward carrier recovery scheme for phase-modulated radio-over-fibre links. In LEOS 200821st Annual Meeting of the IEEE Lasers and Electro-Optics Society IEEE. https://doi.org/10.1109/LEOS.2008.4688861

\section{General rights}

Copyright and moral rights for the publications made accessible in the public portal are retained by the authors and/or other copyright owners and it is a condition of accessing publications that users recognise and abide by the legal requirements associated with these rights.

- Users may download and print one copy of any publication from the public portal for the purpose of private study or research.

- You may not further distribute the material or use it for any profit-making activity or commercial gain

- You may freely distribute the URL identifying the publication in the public portal 


\section{Experimental Demonstration of a Digital Maximum Likelihood based Feedforward Carrier Recovery Scheme for Phase-Modulated Radio-over-Fibre Links \\ Neil Guerrero Gonzalez ,Darko Zibar, Xianbin Xu and Idelfonso Tafur Monroy \\ 1: DTU Fotonik, Department of Photonics Engineering, Ørsteds plads, DK 2800, Kgs. Lyngby, Denmark \\ email: $\underline{n g g @ f o t o n i k . d t u . d k}$}

\begin{abstract}
Maximum likelihood based feedforward RF carrier synchronization scheme is proposed for a coherently detected phasemodulated radio-over-fiber link. Error-free demodulation of $100 \mathrm{Mbit} / \mathrm{s}$ QPSK modulated signal is experimentally demonstrated after $25 \mathrm{~km}$ of fiber transmission.
\end{abstract}

\section{INTRODUCTION}

Transport and distribution of radio and wireless signals over fibre (Radio-over-Fibre RoF) is an important technology in order to realize converged fibre-optic and wireless networks [1]. Optical fibre is gradually becoming a preferred transmission medium, compared to coaxial cable, for connecting central offices and antenna base stations, due to its transmission advantages. Recently, RoF optical links employing optical phase modulation have attracted large attention [2]. Advantages of phase modulated RoF links compared to IM links are: improved linearity, higher RF gain and simpler antenna base station design $[3,4]$ The challenge to implement a phase-modulated optical link lies in the receiver structure since optical phase modulated links require a coherent receiver. We have recently proposed and experimentally demonstrated by proof-of-principle a novel DSP based digital coherent receiver for phase-modulated WDM RoF optical links employing a simple BPSK modulation format for RF carriers [4]. The method of RF carrier synchronization reported in [4] relays on a feedback architecture. However, as we move towards more complex RF modulation schemes, RF carrier and phase synchronization becomes more challenging. The disadvantage of carrier synchronization using feedback is that it cannot be implemented in parallel DSP architectures. Furthermore, the scheme reported in [4] becomes rather complex when moving to higher order modulation formats. Additionally, the processing time will introduce delay within the feedback loop which may result in system instabilities. In this paper, we propose a feedforward maximum likelihood based RF carrier synchronization scheme for phase modulated RoF optical links. Additionally, a digital mean filter is implemented in order to reduce the effects of phase noise and improve signal demodulation. Using the proposed RF carrier synchronization scheme, error-free demodulation for a QPSK phase-modulated RoF optical links (5 GHz RF carrier) is experimentally demonstrated after $25 \mathrm{~km}$ of fibre transmission.

\section{EXPERIMENTAL SET-UP}

The experimental set-up for phase modulated radio-over-fibre optical link is shown in Figure 3. An external cavity tuneable $\mathrm{CW}$ laser $(\sim 100 \mathrm{kHz}$ linewidth $)$ is used at the transmitter. The wavelength of the transmitter laser is at $1550 \mathrm{~nm}$ and the output of the transmitter $\mathrm{CW}$ laser is amplified by high-power EDFA as shown in Fig. 1. A Vector Signal Generator (VSG) is used to generate a $\mathrm{RF}$ carrier $(5 \mathrm{GHz})$ which is modulated by 50 Mbaud QPSK data signal. The RF data signal is then used to drive conventional lithium-niobate optical phase modulator. The phase modulated optical data signal is then send through
$25 \mathrm{~km}$ of SMF and split in two polarizations using PBS Only one polarization is sent to the receiver. At the receiver, a $90^{\circ}$ optical hybrid is used to mix the received data signal with the tunable LO laser sig. $(\sim 3 \mathrm{MHz}$ linewidth).

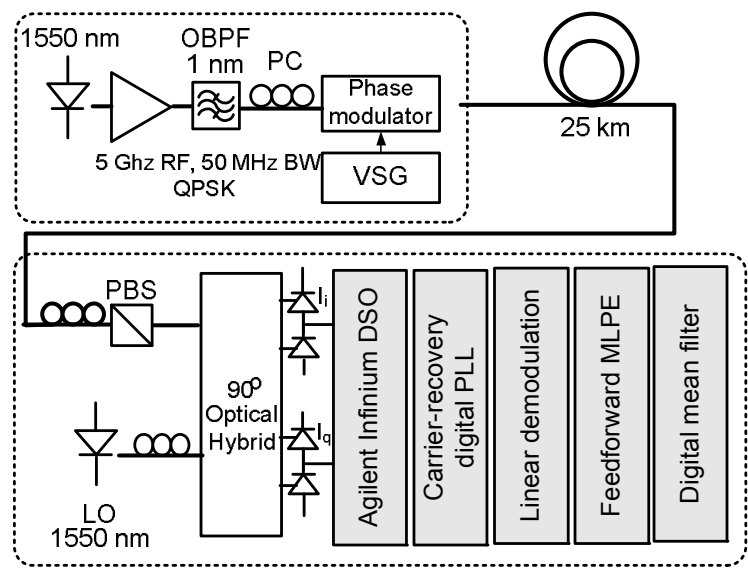

Fig 1. Experimental set-up for the demonstration of coherent phasemodulated RoF optical link. PBS: polarization Beam Splitter, VSG: Vector Signal Generator.

The detected photocurrents are digitalized at sample rate $40 \mathrm{Gs} / \mathrm{s}$ using a high-bandwidth real time sampling scope (Agilent Infinium DSO80000B with $13 \mathrm{GHz}$ analog bandwidth). The sampled photocurrent is later used for offline signal demodulation and data recovery. The postprocessing of the digitized data consists of carrier-recovery digital PLL and linear signal demodulation [4]. Feedforward Maximum Likelihood Phase Estimation (MLPE) stages then used to remove the RF frequency and phase offset from the sampled data signal.

\section{FEEDFORWARD MAXIMUM LIKELIHOOD PHASE ESTIMATION}

Figure 2 shows a block diagram for a feedforward MLPE stage for a $M$-PSK modulation format. Taking the signal to the power of $M$ removes the phase modulation from the $M$ PSK modulated signals. For a sufficiently large number of signal samples, the maximum likelihood phase estimation can be expressed as in eq. (1). Eq. (1) yields estimated values of the signal phases which are wrapped in the range $-\pi$ to $\pi$ because of the range of the tangent function. Therefore, if the sampled signal has a phase that falls outside the $2 \pi$ range, erroneous phase estimation is obtained. This problem is known as ambiguity.

$$
\hat{\phi}=\tan ^{-1}\left(\sum_{n=0}^{N-1} x(n) \sin \left(w_{0} n\right) / \sum_{n=0}^{N-1} x(n) \cos \left(w_{0} n\right)\right)
$$




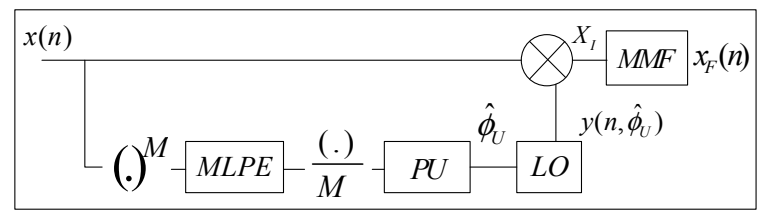

Fig. 2. Feedforward MLPE scheme for RF carrier phase estimation

Therefore, phase unwrapping (PU) is needed in order to remove the phase ambiguity and estimate the accurate value of the phase leading to correct signal demodulation. In this work, we are using detection of sign changes after a signal differentiation operation. Basically, depending on the sign of $d x(n) / d x$ the phase estimated is adjusted or not by a value $\pi$. Finally, a digital mean filter removing the noise and preserving the phase is implemented in order to improve the signal demodulation. The filter is described in eq. (2), where $X_{I}(n)$ is the signal product after the multiplication between $x(n)$ and $y\left(n, \phi_{U}\right), m$ is the size of the filter and $x_{F}(n)$ is the signal after digital filter with the frequency and phase offset removed, see Figure (2).

$$
\left|x_{F}(n)\right|=\frac{1}{2 m} \sum_{N=-m}^{m}\left|X_{I}(n-N)\right| \quad, \quad \arg \left(x_{F}(n)\right)=\arg \left(X_{I}(n)\right)
$$

Using the proposed feedforward RF carrier synchronization algorithm, a constellation diagram of the demodulated QPSK signal is shown in Fig. 3 with and without the digital filter, for the experimental data. Fig. 3 demonstrates that the proposed feedforward algorithm for RF carrier synchronization can be successfully used for QPSK signal demodulation. Additionally, using the digital mean filter, the effect of noise on the constellation points is reduced. (a)

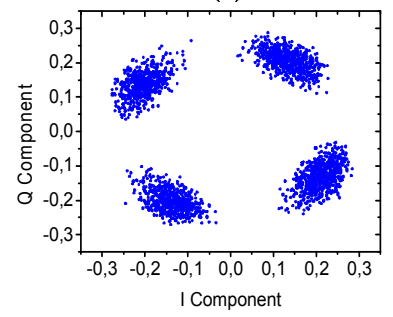

(b)

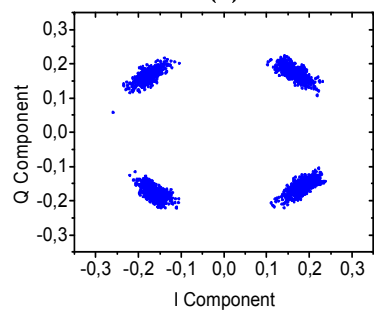

Fig 3. Constellation diagram of the demodulated QPSK signal (a) without filter (b) with digital mean filter

\section{EXPERIMENTAL RESULTS}

In Fig. 4(a), values for the Q-factor of the demodulated $5 \mathrm{GHz}$ RF carrier employing $100 \mathrm{Mb} / \mathrm{s}$ QPSK data modulation are shown for the back-to-back measurement. The signal demodulation and subsequent Q-factor evaluation were performed offline, using the digital coherent receiver shown in Fig. 1. Without employing the digital mean filter it is observed from figure 4(a) that error-free operation (BER better than $10^{-9}$ corresponding to Q larger than $15.6 \mathrm{~dB}$ ) is not achievable. However, as the digital mean filter is employed a significant improvement in Q-factor values is obtained. We observe from Figure 4(a), that the values of the Q-factor of the inphase and quadrature tributaries of the demodulated QPSK signal indicates that error free signal demodulation is obtainable when the digital mean filter is applied. Next, we perform transmission experiments through $25 \mathrm{~km}$ of SMF, which is considered to be a realistic distance between the central office and the antenna base station. Compared to measurement in Fig 4(a), we have optimized the set-up and especially LO power has been optimized. Fig. 4(b) shows the resultant values for the Q-factor of the demodulated 5 $\mathrm{GHz} \mathrm{RF}$ carrier after $25 \mathrm{~km}$ of transmission, respectively. The high values of the Q-factor indicate that error free signal is achieved in the whole considered range of the received optical power levels. The Q-factor values for QPSK format are additionally improved when the digital mean filter is applied.

(a)

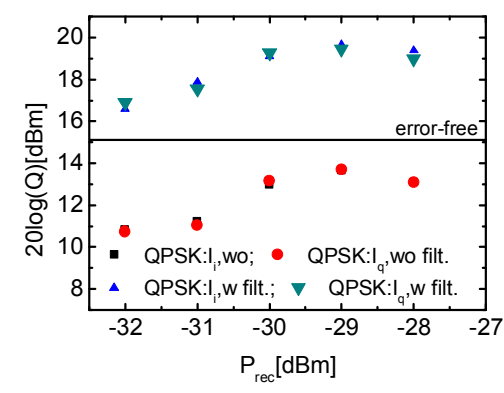

(b)

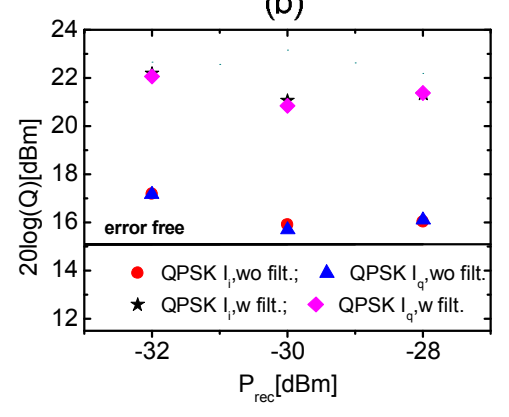

Fig. 4. Q-factor of the demodulated data signal: (a) QPSK back-to-back with and without filter (b) QPSK after $25 \mathrm{~km}$ of transmission with and without filter.

\section{CONCLUSION}

We have experimentally shown that the RF carrier phase estimation based on feedforward maximum likelihood algorithm can be used to successfully recover $100 \mathrm{Mb} / \mathrm{s}$ QPSK signal from phase modulated RoF link (5GHZ RF carrier), after $25 \mathrm{~km}$ of transmission. Likewise, additional digital mean filtering leads to a significant improvement of the Q-factor values.

\section{REFERENCES}

1. J. Capmany et al., Nature, 1, (2007), pp.319-330

2. H. Chou et al., IEEE PTL, 19,(2007), pp.686-688

3. V. J. Urick, IEEE MTT, 9, (2007), pp.1978-1984

4. D. Zibar et al., ECOC (2008), TU.3.E.1. 